\title{
Total pancreatectomy and pancreatic fistula: friend or foe?
}

\author{
Roberto Salvia ${ }^{1}\left[\right.$ ( $\cdot$ Gabriella Lionetto ${ }^{1} \cdot$ Giampaolo Perri $^{1} \cdot$ Giuseppe Malleo $^{1} \cdot$ Giovanni Marchegiani $^{1}$
}

Received: 29 May 2021 / Accepted: 12 July 2021 / Published online: 7 August 2021

(c) The Author(s) 2021

\begin{abstract}
Postoperative pancreatic fistula (POPF) still represents the major driver of surgical morbidity after pancreaticoduodenectomy. The purpose of this narrative review was to critically analyze current evidence supporting the use of total pancreatectomy (TP) to prevent the development of POPF in patients with high-risk pancreas, and to explore the role of completion total pancreatectomy (CP) in the management of severe POPF. Considering the encouraging perioperative outcomes, TP may represent a promising tool to avoid the morbidity related to an extremely high-risk pancreatic anastomosis in selected patients. Surgical management of severe POPF is only required in few critical scenarios. In this context, even if anecdotal, CP might play a role as last resort in expert hands.
\end{abstract}

Keywords Total pancreatectomy $\cdot$ Pancreatic fistula $\cdot$ Completion pancreatectomy $\cdot$ High-risk pancreas

\section{Introduction}

Pancreatic surgery represents a complex surgery, still burdened by high morbidity rates despite advances in surgical technique and perioperative care. Postoperative pancreatic fistula (POPF) remains the major driver of surgical morbidity after pancreaticoduodenectomy (PD). Grade C POPF per the International Study Group of Pancreatic Fistula (ISGPF) definition [1]-i.e., life-threatening fistulae mostly requiring a surgical re-intervention-has an estimated incidence of $2 \%$ with a mortality reaching $35 \%$ [2]. Predictive factors and appropriate management strategies for this dreadful complication are still under scrutiny.

Efforts to prevent severe POPF have often focused on the surgical technique of the pancreatic anastomosis, either a pancreatico-jejunostomy (PJ) or a pancreatico-gastrostomy (PG) with or without stenting [3]. This is particularly true in the high-risk pancreas scenario, where the long-term benefits of pancreatic stump preservation (i.e., lesser incidence of exo-endocrine insufficiency) are mirrored by harsher postoperative courses [4]. Other experience had addressed

Roberto Salvia

roberto.salvia@univr.it

1 Department of Surgery, Dentistry, Gynecology and Pediatrics (DSCOMI), Unit of General and Pancreatic Surgery, University of Verona, G.B. Rossi Hospital, P.Le Scuro 10, 37134 Verona, Italy the same dilemma. In a prospective study, Mazzaferro et al. investigated the safety and efficacy of pancreatic duct occlusion with neoprene-based glue in patients undergoing PD at high risk of POPF. They reported that pancreatic duct occlusion equalizes short-term postoperative outcomes to those patients at lower risk of POPF with, however, a three-fold higher risk of post-surgical diabetes [5].

In this perspective, the encouraging postoperative outcomes of total pancreatectomy (TP) reported at high-volume centers in recent years $[6,7]$ have led the authors questioning whether the burden of complications related to a high-risk pancreatic anastomosis could justify the use of TP as an alternative strategy in selected patients to avoid the occurrence of POPF [8].

Conversely, when a POPF has already developed after PD, salvage surgery may be required after failure of nonoperative strategies [1]. Different intra-operative procedures have been reported, including completion pancreatectomy (CP). CP is a technically demanding operation performed often in critically ill patients due to life-threatening sepsis and/or bleeding, and therefore characterized by a strikingly high mortality (ranging up to $80 \%$ ) [9].

The aim of this review is to critically analyze current evidence supporting the use of TP to prevent POPF in the setting of a high-risk pancreas (a promising new strategy?) and, on the other end, to review the role of CP in the management of severe POPF (the swansong of an obsolete operation?). 


\section{Total pancreatectomy to avoid pancreatic fistula in high-risk patients: a promising new friend?}

Several risk score systems based on pre- and intra-operative parameters, such as the Fistula Risk Score (FRS) [10] or the alternative Fistula Risk Score (a-FRS) [11], have been proposed to predict the occurrence of POPF and stratify patients based on this risk.

The most validated of these scores is the FRS (0-10 points), calculated at the time of pancreatic anastomosis after the pancreatic head resection, on the basis of the weighted influence of 4 risk factors: (1) pancreatic stump texture (firm vs soft); (2) disease pathology (low vs high risk); (3) pancreatic duct size and (4) estimated intra-operative blood loss (Table 1). This score identifies a distinct high-risk cohort (FRS 7-10), which represents around $10 \%$ of all PDs and shows substantially worse clinical outcomes, including a CR-POPF rate approaching 30\% (and up to 100\% in case of FRS 9-10) [4].

Despite the ability to stratify the POPF risk, opinions and controversies upon prevention, mitigation and treatment strategies in high-risk pancreas continue to fuel the debate among surgeons worldwide.

In a recently published randomized trial [12], our group failed to assess superiority of PJ reconstruction over PG for the prevention of POPF in high-risk pancreas. However, the decreased rate of Clavien-Dindo $\geq 3$ ( 23 vs $47 \%$ ) and the lower average complication burden associated with PJ with externalized stent in our experience seems to justify its adoption in this setting. In the era of mitigation strategies [4], this latter finding seems particularly convincing, even when considering the worrisome outcomes related to the externalized stent malfunction, an event occurring in about one-fifth of reported cases and associated with a significantly increased rate of POPF and its severity grade [13].

As mentioned above, recent studies have reported improved perioperative outcomes and postoperative quality of life after TP, presumably due to centralization at highvolume centers and development of long-acting insulin and modern pancreatic enzyme preparations $[6,7,14,15]$.

This has led our group to retrospectively compare shortand long-term outcomes of TP vs PD in patients at high risk for POPF development. Indeed, patients undergoing TP exhibited lower rates of major morbidity (19 vs $31 \%$ ) and a comparable mortality (3 vs $4 \%$ ). Despite these promising postoperative outcomes, performing TP still raises important concerns due to the inevitable presence of its long-term sequelae. In fact, although general, cancer- and pancreas-specific quality of life were comparable between the high-risk PD and TP groups, pancreatic insufficiency affected more severely TP patients with a $100 \%$ endocrine and exocrine insufficiency rate, compared to only $13 \%$ and $63 \%$ in the high-risk PD patients, respectively. Moreover, TP patients showed worse diabetes-related quality-of-life impairment.

Similarly, Capretti et al. reported favorable short-term outcomes in a retrospective cohort of high-FRS patients undergoing intra-operative $\mathrm{CP}$ as an alternative to performing a high-risk pancreatic anastomosis. Notably, decision to perform a TP was often made in older patients with higher ASA score, higher BMI and pre-existing diabetes. The finding of an overall lower complication rate (with a
Table 1 Fistula risk scoring system according to Callery et al. [10]

\begin{tabular}{lll}
\hline Risk factor & Parameter & Points \\
\hline Pancreatic stump texture & Firm & 0 \\
& Soft & 2 \\
Pathology & Low risk (PDAC, chronic pancreatitis) & 0 \\
& High risk (ampullary, duodenal, cystic, pNET, etc.) & 1 \\
Pancreatic duct size (mm) & $\geq 5$ & 0 \\
& 4 & 1 \\
& 3 & 2 \\
& 2 & 3 \\
EBL (ml) & $\leq 1$ & 4 \\
& $\leq 400$ & 0 \\
& $401-700$ & 1 \\
& $701-1000$ & 2 \\
& $>1000$ & 3
\end{tabular}

$E B L$ estimated blood loss, $P D A C$ pancreatic ductal adenocarcinoma, $p N E T$ pancreatic neuroendocrine tumor 
similar-though not significant-trend in major morbidity) in the CP group, corroborated by the absence of major long-term adverse events related to the pancreatic insufficiency, led the authors to consider TP in a selected group of patients, namely those at higher risk of failure to rescue from POPF and those in whom the impact would might be less relevant in the long term [16].

Another possible concern following TP is represented by gastric complications, rarely reported in surgical series, but potentially responsible of severe morbidity and mortality [17]. Indeed, TP necessitates ligation of the right gastric and gastroepiploic veins. Association with splenectomy would impair also the left venous drainage (i.e., splenic vein, left gastroepiploic vein and short gastric vessels), leaving just the coronary vein and the esophageal plexus as major route of gastric venous outflow. Therefore, left gastric vein and spleen preservation must be considered-if oncologically feasible-to preserve the gastric venous outflow and avoid the risk of gastric venous congestion, which may lead to mucosal erosions and hemorrhage and, ultimately, to gastric necrosis and perforation. Furthermore, it is possible to speculate that attempts to preserve the arterial gastric inflow-namely the right gastric artery-could reduce the risk of ischemic complications, considering that usually after a "standard" TP only the left gastric artery provides the global arterial inflow. In this regard, a pylorus-preserving TP with reconstruction by a single jejunal loop with duodenojejunostomy with preservation of right gastric artery followed by hepaticojejunostomy may be effective to minimize the risk of devascularization linked to stomach mobilization (Fig. 1), and also to allow a feasible endoscopic access to manage both the anastomosis in case of related complications and sequelae (Fig. 2).

Unfortunately, data exploring this topic are sparse and come solely from recently published studies [8, 16]. Far from advocating the systematic use of TP in high-risk scenarios, we think that it may be considered as an alternative to perform a high-risk pancreatic anastomosis in highly selected patients for whom the short-term benefits in the postoperative setting may overcome the disadvantages due to the complete absence of residual pancreatic function. For example, it might play a role in oncological patients, for whom access to adjuvant chemotherapy, which is often delayed by the occurrence of POPF [2], could be crucial.

Thus, we are now facing the delicate ethical implications of this decision as we aim to test our hypothesis in a randomized controlled setting. Patients who are deemed to undergo a high-risk anastomosis, after a "pancreasspecific" risk assessment considering main pancreatic duct and pancreatic remnant characteristics, will be sorted to receive either a "standard" reconstruction or

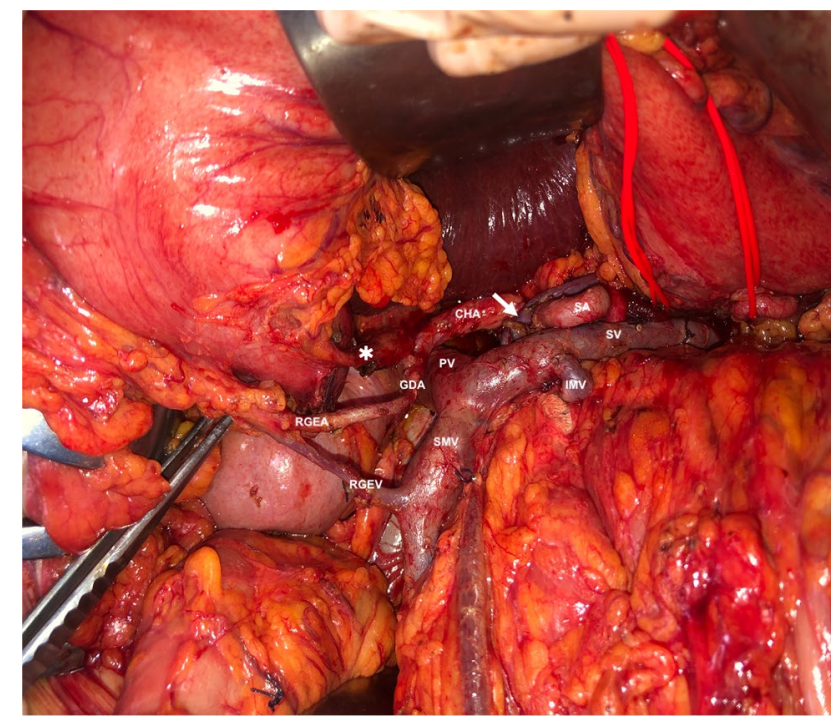

Fig. 1 Operative field after TP with spleen and vessels preservation. The white arrow indicates the left gastric vein, the asterisk the right gastric artery. In this case also, the gastroduodenal artery (GDA), the right gastroepiploic artery (RGEA) and vein (RGEV) were preserved. $C H A$ common hepatic artery, $I M V$ inferior mesenteric vein, $P V$ portal vein, $S M V$ superior mesenteric vein, $S A$ splenic artery, $S V$ splenic vein

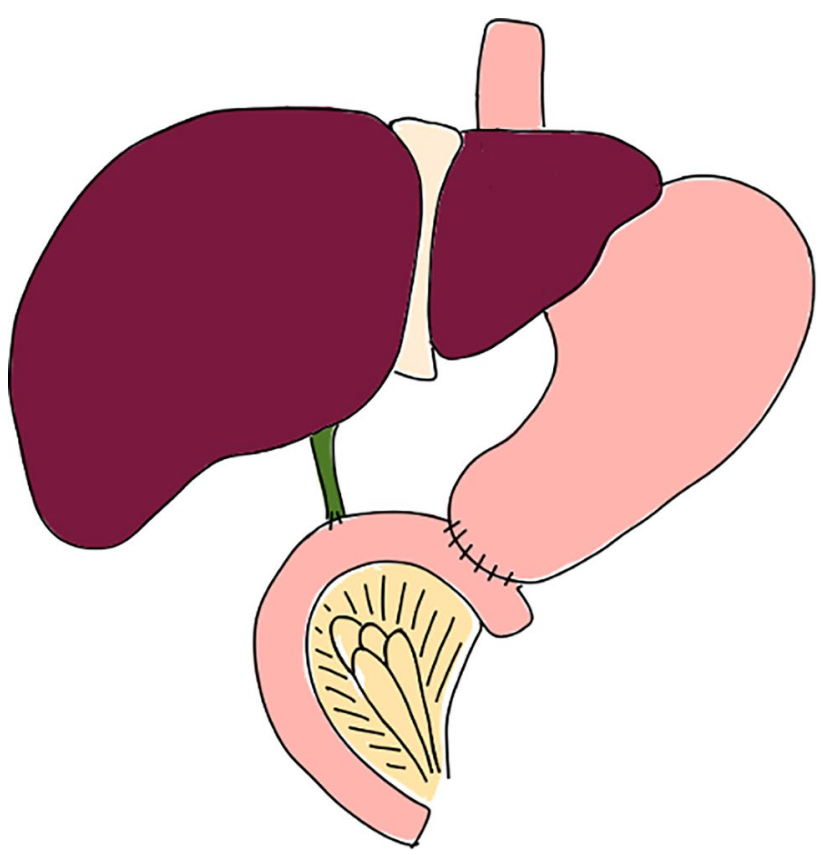

Fig. 2 Reconstruction after TP with a single jejunal loop with duodenojejunostomy followed by hepaticojejunostomy

a completion TP. Postoperative outcomes will be compared together with pancreatic insufficiency and longterm quality of life. 


\section{Total pancreatectomy to treat postoperative pancreatic fistula: the swansong of an obsolete foe?}

Over the last decades there has been a shift from operative to non-operative management of POPF [18]. Although the majority of POPF can be managed with conservative therapy, some do require surgical intervention either because of inaccessibility of infected collection to percutaneous or endoscopic drainage, or because of clinical instability associated with uncontrolled sepsis and multi-organ failure.

To our knowledge, only a systematic review addressed the role of CP in the acute management of fistula [9]. However, despite the heterogeneity between surgical series-all retrospective with inclusion period spanning over two decades - the huge mortality rate stands out.

A systematic search was performed, to provide a broad perspective of the strikingly high mortality of this nowadays rarely performed procedure. A flowchart showing the selection process is available in the Annex. Mortality rates of all major surgical series exploring $\mathrm{CP}$ for POPF are outlined in Table 2. Whether this dismal scenario is linked to the surgical burden itself versus the delay of intervention is debatable.

Indications to $\mathrm{CP}$ are not uniform and depend mostly on a critical patient's fitness for an operation with a median duration ranging from 144 to $240 \mathrm{~min}$ and reported blood loss of 900-2500 $\mathrm{ml}$ [9] Generally, as the median time between elective surgery and CP ranges between 6 and 17 days [9], surgeons have to deal with a surgical field hindered by severe pancreatitis and inflamed surrounding adjacent abdominal organs, where even to get the access to the complication site is a highly demanding procedure. For this reason, $\mathrm{CP}$ is to be considered only in the hands of extremely experienced pancreatic surgeons.

Garnier et al. advocate for earlier threshold for re-exploration in high-risk patients, speculating that in this setting the advantage of performing a CP d'emblée when a pancreatic dehiscence is documented outweighed the resulting exocrine and endocrine insufficiency, given that at least the patient would be alive. Of note they reported lower blood loss rate probably due to the possibility of preserving the spleen in $43 \%$ of the cohort. Unfortunately, given the heterogeneity of scenarios in which CP may be required, it is difficult to reach

Table 2 Overview of major series reporting mortality after CP for POPF management

\begin{tabular}{|c|c|c|c|c|c|c|}
\hline Authors (year) & Period & Number of PD & $\begin{array}{l}\text { Incidence of } \\
\text { POPF n (\%) }\end{array}$ & $\begin{array}{l}\text { Relaparotomy due to } \\
\text { POPF n (\%) }\end{array}$ & $\mathrm{CP} n(\%)$ & $\begin{array}{l}\text { Mortality } \\
\text { after CP } \\
(\%)\end{array}$ \\
\hline Garnier (2021) [19] & 2012-2019 & 450 & $77(17.1)$ & $30(6.7)$ & $21(4.7)$ & 23.8 \\
\hline Luu (2020) [20] & $2007-2016$ & 722 & $125(17.3)$ & $23(3.2)$ & $19(2.6)$ & 36.8 \\
\hline Wronski (2019) [21] & $2003-2017$ & 616 & $67(10.9)$ & $43(7.0)$ & $17(2.8)$ & 47.1 \\
\hline Nentwich (2015) [22] & 2002-2012 & 521 & NA & NA & $20(3.8)$ & 55.0 \\
\hline Almond (2014) [23] & $1987-2013$ & 1232 & NA & NA & $38(3.1)$ & 52.6 \\
\hline Balzano (2014) [24] & 2004-2011 & 669 & $201(30.0)$ & $37(5.5)$ & $14(2.1)$ & 21.4 \\
\hline Ribero (2013) [25] & 1990-2010 & 370 & $112(30.3)$ & $47(10.8)$ & $23(6.2)$ & 43.4 \\
\hline Paye (2013) [26] & $2005-2011$ & 254 & NA & $21(8.2)$ & $4(1.6)$ & 50.0 \\
\hline Govil (2012) [27] & 1999-2006 & 208 & NA & $12(5.8)$ & $2(0.9)$ & 50.0 \\
\hline $\mathrm{Xu}(2010)[28]$ & 1984-2009 & 963 & $103(10.7)$ & $12(1.2)$ & $5(0.5)$ & 20.0 \\
\hline Fuks (2009) [29] & 2000-2006 & 680 & $111(16.3)$ & $36(5.3)$ & $2(0.3)$ & 50.0 \\
\hline Haddad (2009) [30] & 2000-2006 & 117 & $35(29.9)$ & $14(12.0)$ & $5(4.3)$ & 40.0 \\
\hline Bachellier (2008) [31] & $1988-2005$ & 403 & NA & $12(2.9)$ & $8(2.0)$ & 50.0 \\
\hline Müller (2006) [32] & 2001-2006 & NA & NA & NA & 23 (NA) & 39.1 \\
\hline Tamijmarane (2006) [33] & $1987-2005$ & 599 & NA & NA & $23(3.8)$ & 56.5 \\
\hline de Castro (2005) [34] & 1992-1996 & 459 & $41(8.9)$ & NA & $9(2.0)$ & 0.0 \\
\hline Gueroult (2004) [35] & 1989-1999 & 282 & $38(13.5)$ & NA & $8(2.8)$ & 37.5 \\
\hline Schlitt (2002) [36] & $1988-2000$ & 441 & $33(7.5)$ & $29(6.6)$ & $10(2.3)$ & 80.0 \\
\hline van Berge (1998) [37] & 1983-1995 & 269 & $29(10.8)$ & NA & $8(3.0)$ & 0.0 \\
\hline Farley (1996) [38] & 1972-1994 & 458 & NA & NA & $17(3.7)$ & 23.5 \\
\hline Cullen (1994) [39] & 1980-1992 & 375 & $66(17.6)$ & $18(4.8)$ & $7(1.9)$ & 71.4 \\
\hline Smith (1992) [40] & 1964-1988 & 479 & NA & NA & $11(2.3)$ & 63.6 \\
\hline
\end{tabular}

$P D$ pancreaticoduodenectomy, $P O P F$ postoperative pancreatic fistula, $C P$ completion pancreatectomy, $N A$ non-available 
a level of evidence higher than retrospective case-series in this regard (see Table 2).

While we agree that there might be a very selected pool of patients who could benefit from early $\mathrm{CP}$, how to identify them remains nebulous. In our current practice, this operation is exceedingly rarely performed, and reserved for cases in which all other options have been exhausted. Considering the worldwide trends towards a minimally invasive and conservative approach, nowadays it is not difficult to imagine how CP may be more and more relegated to a last resort in critical scenario.

\section{Conclusion}

Considering the encouraging perioperative outcomes, TP may represent a promising "ally" to avoid the morbidity related to a high-risk pancreatic anastomosis in highly selected patients, although important differences in the longterm quality of life remains a major concern to be explored.

Surgical management of POPF is mainly based on surgeon know-how and gut-feeling in an almost always "desperate" situation. In this context, even if anecdotal, CP might sometimes play a role. The best timing for $\mathrm{CP}$, however, still remains a matter of speculation.

Supplementary Information The online version contains supplementary material available at https://doi.org/10.1007/s13304-021-01130-3.

Author contributions GL and GP draft the manuscript. GM and GM critically edited the manuscript. RS reviewed and supervised the paper.

Funding Open access funding provided by Università degli Studi di Verona within the CRUI-CARE Agreement. This paper was not funded.

\section{Declarations}

\section{Conflict of interest None.}

Ethical approval This retrospective chart review study involving human participants was in accordance with the ethical standards of the institutional and national research committee and with the 1964 Helsinki Declaration and its later amendments or comparable ethical standards.

Research involving human participants and/or animals No human partecipants and/or animals were involved.

Informed consent For this type of study informed consent is not required.

Open Access This article is licensed under a Creative Commons Attribution 4.0 International License, which permits use, sharing, adaptation, distribution and reproduction in any medium or format, as long as you give appropriate credit to the original author(s) and the source, provide a link to the Creative Commons licence, and indicate if changes were made. The images or other third party material in this article are included in the article's Creative Commons licence, unless indicated otherwise in a credit line to the material. If material is not included in the article's Creative Commons licence and your intended use is not permitted by statutory regulation or exceeds the permitted use, you will need to obtain permission directly from the copyright holder. To view a copy of this licence, visit http://creativecommons.org/licenses/by/4.0/.

\section{References}

1. Bassi C, Marchegiani G, Dervenis C et al (2017) The 2016 update of the International Study Group (ISGPS) definition and grading of postoperative pancreatic fistula: 11 years after. Surgery 161(3):584-591. https://doi.org/10.1016/j.surg.2016.11.014

2. McMillan MT, Vollmer CMJ, Asbun HJ et al (2016) The characterization and prediction of ISGPF grade $\mathrm{C}$ fistulas following pancreatoduodenectomy. J Gastrointest Surg Off J Soc Surg Aliment Tract 20(2):262-276. https://doi.org/10.1007/s11605-015-2884-2

3. Shrikhande SV, Sivasanker M, Vollmer CM et al (2017) Pancreatic anastomosis after pancreatoduodenectomy: a position statement by the International Study Group of Pancreatic Surgery (ISGPS). Surgery 161(5):1221-1234. https://doi.org/10.1016/j. surg.2016.11.021

4. Ecker BL, McMillan MT, Asbun HJ et al (2018) Characterization and optimal management of high-risk pancreatic anastomoses during pancreatoduodenectomy. Ann Surg 267(4):608-616. https:// doi.org/10.1097/SLA.0000000000002327

5. Mazzaferro V, Virdis M, Sposito C et al (2019) Permanent pancreatic duct occlusion with neoprene-based glue injection after pancreatoduodenectomy at high risk of pancreatic fistula: a prospective clinical study. Ann Surg 270(5):791-798. https://doi.org/ 10.1097/SLA.0000000000003514

6. Pulvirenti A, Pea A, Rezaee N et al (2019) Perioperative outcomes and long-term quality of life after total pancreatectomy. Br J Surg 106(13):1819-1828. https://doi.org/10.1002/bjs.11185

7. Stoop TF, Ateeb Z, Ghorbani P et al (2021) Surgical outcomes after total pancreatectomy: a high-volume center experience. Ann Surg Oncol 28(3):1543-1551. https://doi.org/10.1245/ s10434-020-08957-x

8. Marchegiani G, Perri G, Burelli A et al (2021) High-risk pancreatic anastomosis vs. total pancreatectomy after pancreatoduodenectomy: postoperative outcomes and quality of life analysis. Ann Surg. https://doi.org/10.1097/SLA.0000000000004840 (Published online March 2021)

9. Bressan AK, Wahba M, Dixon E, Ball CG (2018) Completion pancreatectomy in the acute management of pancreatic fi stula after pancreaticoduodenectomy : a systematic review and qualitative synthesis of the literature. Int Hepato-Pancreato-Biliary Assoc 20(1):20-27. https://doi.org/10.1016/j.hpb.2017.08.036

10. Callery MP, Pratt WB, Kent TS, Chaikof EL, Vollmer CMJ (2013) A prospectively validated clinical risk score accurately predicts pancreatic fistula after pancreatoduodenectomy. J Am Coll Surg 216(1):1-14. https://doi.org/10.1016/j.jamcollsurg.2012.09.002

11. Mungroop TH, van Rijssen LB, van Klaveren D et al (2019) Alternative fistula risk score for pancreatoduodenectomy (a-FRS): design and international external validation. Ann Surg 269(5):937-943. https://doi.org/10.1097/SLA.0000000000002620

12. Andrianello S, Marchegiani G, Malleo G et al (2020) Pancreaticojejunostomy with externalized stent vs pancreaticogastrostomy with externalized stent for patients with high-risk pancreatic anastomosis: a single-center, phase 3 randomized clinical trial. JAMA Surg 155(4):313-321. https://doi.org/10.1001/jamasurg.2019. 6035

13. Andrianello S, Marchegiani G, Balduzzi A et al (2020) Pros and pitfalls of externalized trans-anastomotic stent as a mitigation 
strategy of POPF: a prospective risk-stratified observational series. HPB (Oxford). https://doi.org/10.1016/j.hpb.2020.10.025 (Published online November 2020)

14. Stoop TF, Ateeb Z, Ghorbani P et al (2020) Impact of endocrine and exocrine insufficiency on quality of life after total pancreatectomy. Ann Surg Oncol 27(2):587-596. https://doi.org/10.1245/ s10434-019-07853-3

15. Scholten L, Stoop TF, Del Chiaro M et al (2019) Systematic review of functional outcome and quality of life after total pancreatectomy. Br J Surg 106(13):1735-1746. https://doi.org/10. 1002/bjs.11296

16. Capretti G, Donisi G, Gavazzi F et al (2021) Total pancreatectomy as alternative to pancreatico-jejunal anastomosis in patients with high fistula risk score: the choice of the fearful or of the wise? Langenbeck's Arch Surg 406(3):713-719. https://doi.org/10.1007/ s00423-021-02157-1

17. Loos M, Mehrabi A, Ramouz A et al (2021) Gastric venous congestion after total pancreatectomy is frequent and dangerous. Ann Surg. https://doi.org/10.1097/SLA.0000000000004847 (Published online March 2021)

18. Tol JAMG, Busch ORC, van Delden OM, van Lienden KP, van Gulik TM, Gouma DJ (2014) Shifting role of operative and nonoperative interventions in managing complications after pancreatoduodenectomy: What is the preferred intervention? Surgery 156(3):622-631. https://doi.org/10.1016/j.surg.2014.04.026

19. Garnier J, Ewald J, Marchese U, Delpero J, Turrini O (2021) Standardized salvage completion pancreatectomy for grade $\mathrm{C}$ postoperative pancreatic fi stula after pancreatoduodenectomy (with video). Int Hepato-Pancreato-Biliary Assoc. https://doi. org/10.1016/j.hpb.2021.02.005 (Published online)

20. Luu AM, Olchanetski B, Herzog T, Tannapfel A, Uhl W, Belyaev O (2021) Is primary total pancreatectomy in patients with highrisk pancreatic remnant justified and preferable to pancreaticoduodenectomy? -a matched-pairs analysis of 200 patients. Gland Surg 10(2):618-628. https://doi.org/10.21037/gs-20-670

21. Wroński M, Cebulski W, Witkowski B et al (2019) Surgical management of the grade $\mathrm{C}$ pancreatic fistula after pancreatoduodenectomy. HPB (Oxford) 21(9):1166-1174. https://doi.org/10. 1016/j.hpb.2019.01.006

22. Nentwich MF, El AT, Torben G (2015) Salvage completion pancreatectomies as damage control for post-pancreatic surgery complications: a single-center retrospective analysis. World J Surg 39:1550-1556. https://doi.org/10.1007/s00268-015-2969-9

23. Almond M, Roberts KJ, Hodson J et al (2015) Changing indications for a total pancreatectomy: perspectives over a quarter of a century. Am J Med Sci 17(5):416-421. https://doi.org/10.1111/ hpb. 12365

24. Balzano G, Pecorelli N, Piemonti L et al (2014) Relaparotomy for a pancreatic fistula after a pancreaticoduodenectomy: a comparison of different surgical strategies. HPB (Oxford) 16(1):40-45. https://doi.org/10.1111/hpb.12062

25. Ribero D, Amisano M, Zimmitti G, Giraldi F, Ferrero A, Capussotti L (2013) External tube pancreatostomy reduces the risk of mortality associated with completion pancreatectomy for symptomatic fistulas complicating pancreaticoduodenectomy. J Gastrointest Surg Off J Soc Surg Aliment Tract 17(2):332-338. https://doi.org/10.1007/s11605-012-2100-6

26. Paye F, Lupinacci RM, Kraemer A et al (2013) Surgical treatment of severe pancreatic fistula after pancreaticoduodenectomy by wirsungostomy and repeat pancreatico-jejunal anastomosis. Am J Surg 206(2):194-201. https://doi.org/10.1016/j.amjsurg. 2012.10 .039
27. Govil S (2012) Salvage pancreaticogastrostomy for pancreatic fistulae after pancreaticoduodenectomy. Indian J Gastroenterol Off J Indian Soc Gastroenterol 31(5):263-266. https://doi.org/10.1007/ s12664-012-0213-1

28. Xu J, Dai X, Bu X, Gao F, Zhang X (2010) Pancreaticojejunal bridge-anastomosis: a novel option for surgeon to preserve pancreatic body and tail in urgent reoperation for intra-abdominal massive hemorrhage after pancreaticoduodenectomy. World J Surg 34(10):2457-2462. https://doi.org/10.1007/s00268-010-0658-2

29. Fuks D, Piessen G et al (2009) Life-threatening postoperative pancreatic fistula (grade C) after pancreaticoduodenectomy : incidence, prognosis, and risk factors. Am J Surg 197(6):702-709. https://doi.org/10.1016/j.amjsurg.2008.03.004

30. Haddad LBP, Scatton O, Randone B et al (2009) Pancreatic fistula after pancreaticoduodenectomy: the conservative treatment of choice. HPB (Oxford) 11(3):203-209. https://doi.org/10.1111/j. 1477-2574.2009.00007.x

31. Bachellier P, Oussoultzoglou E, Rosso E et al (2008) Pancreatogastrostomy as a salvage procedure to treat severe postoperative pancreatic fistula after pancreatoduodenectomy. Arch Surg 143(10):966-970. https://doi.org/10.1001/archsurg.143.10.966 (Discussion 971)

32. Müller MW, Friess H, Kleeff J et al (2007) Is there still a role for total pancreatectomy? Ann Surg 246(6):965-966. https://doi.org/ 10.1097/SLA.0b013e31815c2ca3

33. Tamijmarane A, Ahmed I, Bhati CS et al (2006) Role of completion pancreatectomy as a damage control option for post-pancreatic surgical complications. Dig Surg 23(4):229-234. https://doi. org/10.1159/000095395

34. de Castro SMM, Busch ORC, van Gulik TM, Obertop H, Gouma DJ (2005) Incidence and management of pancreatic leakage after pancreatoduodenectomy. Br J Surg 92(9):1117-1123. https://doi. org/10.1002/bjs.5047

35. Gueroult S, Parc Y, Duron F, Paye F, Parc R (2004) Completion pancreatectomy for postoperative peritonitis after pancreaticoduodenectomy: early and late outcome. Arch Surg 139(1):16-19. https://doi.org/10.1001/archsurg.139.1.16

36. Schlitt HJ, Schmidt U, Simunec D et al (2002) Morbidity and mortality associated with pancreatogastrostomy and pancreatojejunostomy following partial pancreatoduodenectomy. Br J Surg 89(10):1245-1251. https://doi.org/10.1046/j.1365-2168.2002. 02202.x

37. van Berge Henegouwen MI, De Wit LT, Van Gulik TM, Obertop H, Gouma DJ (1997) Incidence, risk factors, and treatment of pancreatic leakage after pancreaticoduodenectomy: drainage versus resection of the pancreatic remnant. J Am Coll Surg 185(1):18 24. https://doi.org/10.1016/s1072-7515(97)00007-0

38. Farley DR, Schwall G, Trede M (1996) Completion pancreatectomy for surgical complications after pancreaticoduodenectomy. Br J Surg 83(2):176-179

39. Cullen JJ, Sarr MG, Ilstrup DM (1994) Pancreatic anastomotic leak after pancreaticoduodenectomy: incidence, significance, and management. Am J Surg 168(4):295-298. https://doi.org/10.1016/ s0002-9610(05)80151-5

40. Smith CD, Sarr MG, vanHeerden JA (1992) Completion pancreatectomy following pancreaticoduodenectomy: clinical experience. World J Surg 16(3):521-524. https://doi.org/10.1007/BF02104459

Publisher's Note Springer Nature remains neutral with regard to jurisdictional claims in published maps and institutional affiliations. 